\title{
Pricing Rice Quality Attributes and Returns to Quality Upgrading in Sub-Saharan Africa
}

\author{
Edgar E. Twine ${ }^{1 \star(D)}$, Sali Atanga Ndindeng ${ }^{2}$, Gaudiose Mujawamariya ${ }^{3}$ and Koichi Futakuchi ${ }^{2}$ \\ ${ }^{1}$ Africa Rice Center, C/O National Crops Resources Research Institute, Kampala, Uganda, ${ }^{2}$ Africa Rice Center, M’bé Research \\ Station, Bouaké, Côte d'Ivoire and ${ }^{3}$ Africa Rice Center, Antananarivo, Madagascar \\ ${ }^{*}$ Corresponding author: Email: E.Twine@cgiar.org
}

\begin{abstract}
The study applies parametric and nonparametric estimation methods to determine hedonic prices of rice quality attributes, and a partial equilibrium model to determine the payoff to investing in quality improvement in five countries in Sub-Saharan Africa. Results indicate that consumers are willing to pay price premiums for head rice, slender grains, peak viscosity, parboiled rice, and rice sold in urban markets. However, they strongly discount amylose content, rice with impurities and imported rice. Investing in quality improvement through amylose content reduction leads to net welfare gains with a benefit-cost ratio of 47.86 and internal rate of return of $90 \%$.
\end{abstract}

Keywords: hedonic pricing; parametric and nonparametric estimation; producer and consumer welfare; rice quality improvement; Sub-Saharan Africa

JEL classifications: C14; D12; D61; Q11; Q16

\section{Introduction}

The 2008 dramatic rise in global rice prices following export restrictions by India and Vietnam caused food insecurity and subsequently social unrest in several African countries such as Cameroon (Slayton, 2009). These events were a wake-up call for African governments to pursue import substitution by accelerating investments in domestic rice production to achieve full selfsufficiency. Since then, improving self-sufficiency-defined as the ratio of domestic production to total consumption-has been a strategic policy goal. Self-sufficiency ratios have increased from $53 \%$ in 2011 to $77 \%$ in 2020 for Nigeria, 33\% in 2009 to 50\% in 2020 for Cote d'Ivoire, $24 \%$ in 2009 to $35 \%$ in 2020 for Ghana, $9 \%$ in 2010 to $26 \%$ in 2020 for Cameroon, and $85 \%$ in 2008 to $88 \%$ in 2020 for Madagascar ${ }^{1}$.

However, efforts to increase self-sufficiency have often involved the use of import restrictions (Coulibaly et al., 2015; United States Department of Agriculture (USDA), 2018). Given the low quality of domestic rice relative to imported rice in these countries (Akoa Etoa et al., 2016; Cadoni and Angelucci, 2013; Ndindeng et al., 2021a; Obih and Baiyegunhi, 2017; Republic of Cameroon, 2009; Republic of Ivory Coast, 2012), these import restrictions are essentially protecting poor quality rice at the expense of consumer welfare. The $35 \%$ common external tariff proposed by West African rice producers has been shown to reduce consumer welfare (Coulibaly et al., 2015). A more reasonable strategy to enhancing the competitiveness of domestic rice is to improve both farm productivity and grain quality (Erenstein et al., 2004). Existing studies, however, have

\footnotetext{
${ }^{1}$ Calculated from data contained in the United States Department of Agriculture (2020) production, supply, and distribution dataset on grains and pulses.

( The Author(s), 2022. Published by Cambridge University Press on behalf of the Southern Agricultural Economics Association. This is an Open Access article, distributed under the terms of the Creative Commons Attribution licence (https://creativecommons.org/licenses/by/4.0/), which permits unrestricted re-use, distribution, and reproduction in any medium, provided the original work is properly cited.
} 
Table 1. Agricultural R\&D spending, research intensity, and number of researchers in Nigeria, Ghana, Cote d'Ivoire, Cameroon, and Madagascar

\begin{tabular}{|c|c|c|c|c|c|}
\hline & Nigeria $^{a}$ & Ghanab & $\begin{array}{l}\text { Cote } \\
\text { d'Ivoire }^{c}\end{array}$ & Cameroon $^{\text {d }}$ & Madagascar $^{\mathrm{e}}$ \\
\hline $\begin{array}{l}\text { Total agricultural R\&D spending (million, constant PPP } \\
\text { US\$) }\end{array}$ & 433.5 & 178.6 & 77.7 & 54.6 & 10.4 \\
\hline $\begin{array}{l}\text { Agricultural research intensity (agricultural R\&D spend- } \\
\text { ing as a \% of agricultural GDP) }\end{array}$ & 0.22 & 0.91 & 0.50 & 0.38 & 0.14 \\
\hline Number of researchers per 100,000 farmers (FTEs) & 23.7 & 8.6 & 10.1 & 7.7 & 2.4 \\
\hline
\end{tabular}

asource: Beintema et al. (2017).

${ }^{b}$ Source: Flaherty et al. (2018).

'Source: Domgho et al. (2018a).

${ }^{d}$ Source: Domgho et al. (2018b).

eSource: Domgho et al. (2018c).

calculated either producer surplus when determining the welfare effects of varietal improvement for greater farm productivity [see Dalton and Guei (2003) for the case of seven West African countries], or only consumer surplus when examining the welfare effects of varietal improvement for better grain quality [see Ndindeng et al. (2021b) for the case of Benin].

What is the effect of improvement in grain quality, through breeding, on the welfare of both producers and consumers, and what is the net welfare gain? Is it worthwhile for countries in SSA to invest in breeding for better grain quality? Using data from Nigeria, Cameroon, Cote d'Ivoire, Ghana, and Madagascar, the study attempts to answer these questions to inform ongoing varietal development and seed production programs in SSA, considering tightening research-for-development budgets and ongoing efforts to develop product profiles for rice varietal improvement. Rice breeding in SSA has been driven by national agricultural research and development (R\&D) systems, with the support of the Africa Rice Center, International Rice Research Institute, International Center for Tropical Agriculture, International Institute of Tropical Agriculture, and Centre de coopération internationale en recherche agronomique pour le développement. For the countries in this study, rice research is led by the National Cereals Research Institute (NCRI) in Nigeria, the Institute of Agricultural Research for Development (Institut de Recherche Agricole pour le Développement) in Cameroon, the National Center for Agricultural Research in Cote d'Ivoire, the Crops Research Institute and the Savanna Agricultural Research Institute in Ghana, and the Centre National de la Recherche Appliquée au Développement Rural (FOFIFA) in Madagascar. A systematic continent-wide product-oriented approach to rice breeding was adopted by the Global Rice Science Partnership (GRiSP) with the goal of developing high yielding varieties with grain quality attributes that meet consumer demand (Kumashiro et al., 2013). However, national R\&D systems and programs vary in strength; some undertake the full range of breeding activities to produce varieties suited to their rice ecologies and markets, while others simply test lines that have been developed elsewhere (Sanni et al., 2013). This reinforces the need for information that is relevant to setting priorities for research. Differences in the strength of national R\&D systems can be seen in Table 1 . Nigeria has the largest agricultural R\&D spending and number of researchers per 100,000 farmers, but its research intensity is relatively low. The NCRI alone has three rice breeders (Waithaka et al., 2019), and although it has so far developed and released 63 varieties for different ecologies (National Cereals Research Institute, 2021), their quality has been low (Takeshima and Maji, 2016). Ghana has the highest research intensity, while Madagascar has the lowest values of the three parameters. Interestingly, Madagascar is the only country that is nearly fully self-sufficient in rice. 
Up-to-date information on how much national R\&D systems have spent on rice research alone and the impact of that spending is very scarce. But we believe it has been inadequate for the most part, just as it has been for entire research institutes [see, for instance, Adejumo-Ayibiowu (2010) for the case of the NCRI]. In Ghana, total funding for all the country's 13 research institutes was 31.65 million cedis in 2012 (Essegbey and Asare, 2014). This meant an average of 2.43 million cedis or approximately US\$1.3 million per institute. In Cameroon, rice had the second highest breeding budget in 1985-about $20 \%$ of the total budget - after maize (with about $30 \%$ ), but by 2001, it had declined to less than $10 \%$ (Falck-Zepeda et al., 2008). In the same period, 18 rice varieties were released (Falck-Zepeda et al., 2008) and by 2009, 52.1\% of the of the country's 99,653 hectares of rice were under improved varieties (Agricultural Science \& Technology Indicators (ASTI), 2021). The country's 10-year national strategy for rice sector development (2009-2018) supported breeding of improved varieties and the expected cost of research activities included in the strategy was FCFA 27.06 billion (Republic of Cameroon, 2009), equivalent to about US\$ 54 million for the 10 years. It is not known to what extent actual allocations met the expected cost.

This study has three objectives. The first objective is to estimate hedonic prices of rice quality attributes in the selected countries. We use data obtained from laboratory tests of physicochemical characteristics of rice samples purchased from different markets in the five countries. In estimating the hedonic price model, however, we are confronted with the issue of functional form. It is widely acknowledged in the literature that a hedonic price function is inherently nonlinear since the differentiated products are sold in separate but interrelated markets, and its curvature derives from that of firms' profit functions and consumers' utility functions (Costanigro and McCluskey, 2011; Rosen, 1974). Moreover, economic theory does not prescribe a functional form specification for it and therefore the widely assumed additive separability of attributes is simply an econometric construct (Bin, 2000; Costanigro and McCluskey, 2011; Cropper et al., 1988; Halvorsen and Pollakowski, 1981; Jordan et al., 1985; Lisi, 2013; Rosen, 1974). This has elicited considerable interest in the use of nonparametric and semiparametric methods to estimate hedonic price models. But their application to the analysis of consumer preference for food quality attributes remains scanty. Therefore, the second objective is to compare parametric with nonparametric specifications. The third objective is to examine potential changes in producer and consumer welfare and returns to public investment in upgrading the quality of rice through genetic improvement. To this end, we apply the estimated hedonic prices to a partial equilibrium model.

We find the nonparametric specification of the hedonic price model to fit the data better than its parametric counterpart. The results suggest that rice consumers in SSA are willing to pay price premiums for slender grains, intact grains, parboiled rice, rice sold in urban markets, and rice with greater peak viscosity. However, they discount imported rice, rice with impurities, and with high amylose content. Furthermore, we see gains in net welfare from a reduction in amylose content. Therefore, policy makers in SSA ought to devise policies that support greater investment in rice $\mathrm{R} \& \mathrm{D}$ that leads to consumer-preferred traits, which would in turn improve the competitiveness of domestic rice.

Our paper makes two major contributions, the first of which is methodological and concerns the application of parametric and nonparametric techniques to a hedonic price model of a food product. Despite eliminating all assumptions and structure from the econometric model and including dummy variables in it, the nonparametric specification provides relatively credible results. Second, the evidence generated is highly relevant to ongoing efforts by national and international rice $\mathrm{R} \& \mathrm{D}$ organizations involved in market intelligence and the development of rice product profiles that meet consumer preferences. These efforts, which are led by CGIAR, require proper priority setting given the scarcity of resources for investing in crop improvement.

The rest of the paper is organized as follows. Section two reviews related literature, while section three describes the theoretical framework. This is followed in section four by a discussion of the data and descriptive statistics of some variables. The empirical approach is presented in section 
five, and the results, estimation issues and limitations of the study are discussed in section six. Section seven summarizes and concludes the paper with implications for estimating hedonic price models of food quality attributes and upgrading of rice value chains in SSA.

\section{Related Literature}

Studies that have estimated hedonic prices of rice quality attributes include Unnevehr (1986) for Thailand, Indonesia, and the Philippines, Naseem et al. (2013) for Benin, Cuevas et al. (2016) for the Philippines, and more recently Ndindeng et al. (2021b) for Benin. Like the current study, Unnevehr (1986), Cuevas et al. (2016), and Ndindeng et al. (2021b) use data obtained from laboratory analyses of rice samples, but they employ only parametric methods to estimate their models. Using similar approaches, Unnevehr (1986) and Ndindeng et al. (2021b) estimate the impacts on consumer surplus of grain quality improvement, but Unnevehr (1986) goes even further to calculate the associated returns, which she finds to be substantial. From the breeding efforts prior to her study, improvement in head rice recovery had a benefit-cost ratio (BCR) of 49 and internal rate of return (IRR) of $61 \%$ for the Philippines and Indonesia combined, while reduction in amylose content for rice in Indonesia had a BCR of 8 and IRR of 37. Future reduction in amylose content in the Philippines was expected to yield a BCR of 9 and IRR of 29. Ndindeng et al. (2021b) have found rather small gains in consumer surplus if there is an increase in head rice and a reduction in chalkiness. The hedonic price model in both studies is the consumer goods characteristics model (CGCM) of Ladd and Suvannunt (1976). The CGCM is appealing because unlike in Lancaster (1966) model, marginal utilities and hence hedonic prices are not required to be nonnegative (Ladd and Suvannunt 1976). However, Unnevehr (1986) and Ndindeng et al. (2021b) would not have been able to calculate changes in producer surplus because the CGCM is derived only from the consumer side of the market (Unnevehr, 1992). And in the context of our study, it does not lend itself to nonparametric estimation because it is strictly linear (Abansi et al., 1992).

There has been a significant increase in product differentiation in agrifood markets, which calls for researchers to address, among other empirical issues, the functional form of the hedonic price model (Costanigro and McCluskey, 2011). However, only a handful of authors have weighed in on the methodological debate around parametric and non/semiparametric methods in the context of their substantive application to agrifood commodities and products. In estimating a hedonic price model for cattle in rural Ethiopia, Kassie (2007) downplays the need to take into consideration the different estimation methods if the main aim is to estimate the first-stage regression of Rosen's (1974) procedure. But this is not entirely correct as demonstrated by other studies. Bonanno et al. (2019) estimate only the first-stage regression of the hedonic price model of yogurt in Italy. Although they use parametric methods, they acknowledge that given the large number of binary regressors in their model, a nonparametric method would have been helpful in identifying the relevant regressors. Kwong et al. (2011) and Kwong et al. (2017) find semiparametric hedonic price models to fit Ontario's dry red wines data better than parametric ones. Nonetheless, hedonic pricing studies in the agrifood and beverages literature have generally stuck to parametric estimation (see, for instance, Costanigro et al., 2009; Cuevas et al., 2016; Espinosa and Goodwin, 1991; Naseem et al., 2013). Some have attempted to combine parametric and nonparametric methods. Costanigro et al. (2009) introduce the Local Polynomial Regression Clustering procedure, which combines nonparametric and parametric methods. It applies the former in the first step to generate local observation-specific estimates of the hedonic price function, and the latter in the final step to estimate hedonic price functions of different segments found in the data.

The risk of functional form misspecification in parametric hedonic price models is real. But nonparametric and semiparametric models are not without problems either. Nonparametric models suffer from two major problems (Kwong et al., 2011): first, they can be difficult to interpret if they have many explanatory variables, and second, they tend to suffer from the so-called "curse of 
dimensionality problem" revealed by Friedman and Stuetzle (1981); because hedonic price data sets tend to be small, yet the number of attributes is usually large, nonparametric estimators converge rather slowly and may consequently not achieve the desired precision. Semiparametric models, which consist of parametric and nonparametric components, are supposed to alleviate the curse of dimensionality. However, they too will be problematic if the variables that enter the parametric part are not known with certainty (Parmeter et al., 2007) as is the case in our study. The debate between parametric and non/semiparametric methods has perhaps been even more heated in the housing literature without signs of drawing closer to a consensus (see, e.g., Anglin and Gençay, 1996; Bao and Wan, 2004; Bin, 2000; Bontemps et al., 2008; Coulson, 1992; Gençay and Yang, 1996; Haupt et al., 2010; Landajo et al., 2012; Lee, 2013; Martins-Filho and Bin, 2005; Mason and Quigley, 1996; Meese and Wallace, 1991; Pace, 1993, 1995; Parmeter et al., 2007). It is for these reasons that we capitalize on our relatively large data set to test for a parametric versus nonparametric specification.

\section{Theoretical Framework}

Rosen (1974) derives a model of product differentiation in a competitive market based on Lancaster's (1966) idea that consumers derive utility not from goods per se, but from their attributes or characteristics. While Lancaster (1966) emphasizes consumer behavior and does not delve into issues of market equilibrium, Rosen (1974) places a market between producers and consumers. Assume a competitive market in which several types or brands of rice can be described by $n$ objectively measurable quality attributes. The vector of rice types is $X=\left(x_{1}, \ldots \ldots \ldots, x_{n}\right)$ with $x_{i}$ measuring the quantity of attribute $i$ contained in each type of rice. Each rice type has an observed market price and a fixed value of the vector $X$ so that markets of the different types of rice are characterized by a function

$$
P(X)=P\left(x_{1}, \ldots \ldots ., x_{n}\right)
$$

relating price to attributes. This is the hedonic or implicit price function. The price $P(X)$ is determined by market clearing conditions arising from the maximizing behavior of consumers and producers. On the consumers' side, suppose a consumer buys one unit of a type of rice and their utility function is defined as $U\left(z, x_{1}, \ldots \ldots \ldots, x_{n}\right)$ where $z$ is all other goods consumed. If the price of $z$ is set to unity, the consumer's income, $y$, in terms of the price of $z$ is

$$
y=z+P(X)
$$

The consumer maximizes utility subject to the nonlinear budget constraint. Let us define $y-z=\theta$ as the budget for buying a certain type of rice. Then $\theta\left(x_{1}, \ldots \ldots \ldots, x_{n} ; y, u^{*}\right)$ is the bid or value function, defined as the maximum amount a consumer is willing to pay as a function of income and attributes at a fixed utility index. And $P(X)$ is the minimum price they must pay in the market. Therefore, utility is maximized when

$$
\theta\left(X^{*} ; y, u^{*}\right)=P\left(X^{*}\right)
$$

where $X^{*}$ and $u^{*}$ are optimum quantities. On the producers' (sellers') side, a producer aims to maximize profit, $\pi$, subject to their production technology. Their unit revenue is $P(X)$. The producer will have an offer function $\emptyset\left(x_{1}, \ldots \ldots ., x_{n} ; \pi, \vartheta\right)$ where $\vartheta$ is a shift parameter that represents factor prices and production function parameters. The offer function is the minimum amount the producer is willing to accept as a function of costs and attributes at a given level of profit. Since $P(X)$ is the maximum price they can get in the market, profit is maximized when

$$
\emptyset\left(X^{*}, \pi^{*}, \vartheta\right)=P\left(X^{*}\right)
$$

where $\pi^{*}$ is optimum profit. Thus, market equilibrium occurs when the buyer's bid function and the seller's offer function touch, and their common slope is equal to the slope of the equilibrium hedonic price function $P(X)$. 
Hedonic price theory does not exactly specify the nature of the relationship between prices and attributes. According to Rosen (1974), it should be estimated with the best fitting functional form, and the resulting coefficients are the implicit marginal prices (also known as shadow or hedonic prices) of the attributes. A positive coefficient on an attribute implies that consumers are willing to pay a price premium for that attribute, while a negative coefficient implies that consumers discount the attribute.

\section{Data and Descriptive Statistics}

Data for the hedonic price model were obtained from rice samples collected from five countries, namely, Nigeria, Ghana, and Cote d'Ivoire in West Africa, Cameroon in Central Africa, and Madagascar in Eastern Africa. Rice is a major source of calories in these countries, but the level of rice sector development varies from one country to another. A protocol for collecting rice samples was implemented to avoid inconsistencies in recording market prices and to ensure that the samples are representative of the rice consumed in each country. In each country, the major regions of rice production and consumption were identified, and some were randomly selected for rice sample collection ${ }^{2}$. Within the selected regions, rural and urban physical rice markets were randomly selected. Urban areas are characterized by a continuum of markets from low to high end. This was taken into consideration in market selection. In each market, rice retailers were randomly selected, and one rice sample of at least $0.25 \mathrm{~kg}$ was purchased from each retailer at the asking price. Where a retailer sold more than one type of rice, the purchased sample was randomly selected. A total of 1,234 samples were purchased: 305 from Cameroon, 387 from Cote d'Ivoire, 204 from Ghana, 182 from Madagascar, and 156 from Nigeria.

Rice samples were analyzed in a grain quality laboratory for different physicochemical characteristics that influence quality and hence market price. They include impurities, head rice (proportion of intact grains), length-width ratio (grain shape), chalkiness (white belly or opaque portion of the grain), lightness (whiteness), amylose content, color intensity, and viscosity (peak, breakdown, and final). Amylose content and viscosity are chemical properties that influence the cooking quality of rice. A high amylose content makes rice less sticky and less tender when cooked, while viscosity determines the pasting quality of rice when cooked. For instance, a high peak viscosity means that cooked rice will swell more and have reduced firmness on cooling. Other important characteristics that may influence consumers' perception of quality include origin (domestic or imported), type of market (rural or urban), and type of rice (parboiled or nonparboiled/white), all of which are captured as dummy variables.

Descriptive statistics of the variables used in the regression models are summarized in Table 2 for individual countries and Table 3 for the pooled data. Two variables are particularly important for cross-country comparison-average market prices and level of impurities. To meaningfully compare market prices, each country's rice prices were converted to constant international dollars using the country's Purchasing Power Parity conversion factor for private consumption ${ }^{3}$ from the World Bank's World Development Indicators database (World Bank, 2020). Table 2 shows that on average, rice is most expensive in Ghana at $2.25 \mathrm{USD} / \mathrm{kg}$, followed by Cameroon at $1.99 \mathrm{USD} /$ $\mathrm{kg}$, and is least expensive in Madagascar at $1.52 \mathrm{USD} / \mathrm{kg}$.

\footnotetext{
${ }^{2}$ Samples were collected from Gbeke, Hambol, and Bélier regions of Cote d'Ivoire in 2020, Vakinankaratra and Atsimo Andrefana regions of Madagascar in 2019, Central, Northwest, Southwest, Northern, Adamawa, and Littoral regions of Cameroon in 2019, North Central and North West regions of Nigeria in 2019, and Upper East and Upper West regions of Ghana in 2014.

${ }^{3}$ The 2019 conversion factors in local currency units per international dollar were as follows: 235.22 (Cameroon), 235.17 (Cote d'Ivoire), 1.94 (Ghana), 134.21 (Nigeria), and 1,058.87 (Madagascar). Without considering PPP, average prices in USD/ $\mathrm{kg}$ were 0.81 (Cameroon), 0.74 (Cote d'Ivoire), 1.03 (Ghana), 0.69 (Nigeria), and 0.44 (Madagascar). Exchange rates at the time of the surveys were $1 \mathrm{USD}=580.00 \mathrm{XAF}, 553.90 \mathrm{XOF}, 4.26 \mathrm{GHC}, 360.00 \mathrm{NGN}$, and 3643.00 MGA.
} 
Table 2. Summary statistics for individual countries

\begin{tabular}{|c|c|c|c|c|c|}
\hline Variable & Country & Mean & Std. Dev & Min & Max \\
\hline \multirow[t]{5}{*}{ Price (P, USD/kg) } & Nigeria & 1.86 & 0.66 & 1.10 & 8.34 \\
\hline & Ghana & 2.25 & 0.98 & 1.30 & 5.93 \\
\hline & Cote d'Ivoire & 1.74 & 0.52 & 1.18 & 7.82 \\
\hline & Cameroon & 1.99 & 0.58 & 1.43 & 4.93 \\
\hline & Madagascar & 1.52 & 0.16 & 0.93 & 1.96 \\
\hline \multirow[t]{5}{*}{ Impurities (I, \%) } & Nigeria & 1.03 & 1.22 & 0.00 & 7.05 \\
\hline & Ghana & 4.97 & 8.64 & 0.00 & 59.11 \\
\hline & Cote d'Ivoire & 1.30 & 3.18 & 0.00 & 48.15 \\
\hline & Cameroon & 0.26 & 0.54 & 0.00 & 3.00 \\
\hline & Madagascar & 3.64 & 3.68 & 0.00 & 28.25 \\
\hline \multirow[t]{5}{*}{ Head rice (HR, \%) } & Nigeria & 91.17 & 9.03 & 58.87 & 99.96 \\
\hline & Ghana & 87.97 & 11.66 & 45.16 & 99.98 \\
\hline & Cote d'Ivoire & 77.19 & 23.11 & 1.96 & 99.83 \\
\hline & Cameroon & 92.57 & 9.50 & 44.00 & 99.85 \\
\hline & Madagascar & 74.86 & 11.67 & 36.73 & 98.87 \\
\hline \multirow{5}{*}{$\begin{array}{l}\text { Length-Width ratio } \\
\text { (LWR) }\end{array}$} & Nigeria & 2.99 & 0.38 & 2.29 & 4.21 \\
\hline & Ghana & 3.08 & 0.27 & 0.65 & 3.52 \\
\hline & Cote d'Ivoire & 2.78 & 0.39 & 0.03 & 4.31 \\
\hline & Cameroon & 3.12 & 0.39 & 1.91 & 3.68 \\
\hline & Madagascar & 2.53 & 0.34 & 1.16 & 3.64 \\
\hline \multirow[t]{5}{*}{ Chalkiness (C, \%) } & Nigeria & 2.14 & 6.40 & 0.00 & 50.04 \\
\hline & Ghana & 14.67 & 20.43 & 0.00 & 81.05 \\
\hline & Cote d'Ivoire & 22.05 & 18.44 & 0.00 & 77.00 \\
\hline & Cameroon & 7.74 & 11.14 & 0.00 & 60.09 \\
\hline & Madagascar & 13.54 & 11.20 & 0.00 & 61.11 \\
\hline \multirow[t]{5}{*}{ Lightness (L, \%) } & Nigeria & 52.46 & 4.46 & 42.41 & 69.29 \\
\hline & Ghana & 61.55 & 6.67 & 42.99 & 72.98 \\
\hline & Cote d'Ivoire & 57.53 & 6.67 & -0.52 & 67.07 \\
\hline & Cameroon & 58.66 & 5.46 & 45.71 & 71.06 \\
\hline & Madagascar & 57.15 & 3.94 & 42.38 & 68.28 \\
\hline \multirow{5}{*}{$\begin{array}{l}\text { Amylose content } \\
(\mathrm{AC}, \%)\end{array}$} & Nigeria & 24.18 & 1.55 & 21.64 & 28.93 \\
\hline & Ghana & 24.22 & 4.69 & 12.73 & 32.11 \\
\hline & Cote d'Ivoire & 23.91 & 1.53 & 21.57 & 31.14 \\
\hline & Cameroon & 24.78 & 0.94 & 21.94 & 27.28 \\
\hline & Madagascar & 23.68 & 0.79 & 22.20 & 26.96 \\
\hline
\end{tabular}

(Continued) 
Table 2. (Continued)

\begin{tabular}{|c|c|c|c|c|c|}
\hline Variable & Country & Mean & Std. Dev & Min & Max \\
\hline \multirow[t]{5}{*}{ Color intensity $(\mathrm{Cl})$} & Nigeria & 9.91 & 1.32 & 7.40 & 14.51 \\
\hline & Ghana & 11.74 & 2.38 & 7.24 & 26.29 \\
\hline & Cote d'Ivoire & 8.38 & 5.05 & 4.19 & 63.90 \\
\hline & Cameroon & 10.56 & 1.59 & 2.27 & 19.06 \\
\hline & Madagascar & 8.88 & 1.09 & 6.14 & 11.43 \\
\hline \multirow{5}{*}{$\begin{array}{l}\text { Peak viscosity (PV, } \\
\text { centipoise) }\end{array}$} & Nigeria & 361.44 & 550.78 & 42.00 & $2,468.00$ \\
\hline & Ghana & $1,346.98$ & 840.07 & 38.00 & $3,418.50$ \\
\hline & Cote d'Ivoire & $1,952.06$ & 812.73 & 119.00 & $3,898.00$ \\
\hline & Cameroon & 797.55 & 536.41 & 35.00 & $2,639.50$ \\
\hline & Madagascar & $2,433.17$ & 626.39 & 876.00 & $3,777.00$ \\
\hline \multirow{5}{*}{$\begin{array}{l}\text { Type of market (TM, } \\
\text { Urban }=1 \text {, Rural }=0 \text { ) }\end{array}$} & Nigeria & 0.46 & 0.50 & 0.00 & 1.00 \\
\hline & Ghana & 0.63 & 0.48 & 0.00 & 1.00 \\
\hline & Cote d'Ivoire & 0.64 & 0.48 & 0.00 & 1.00 \\
\hline & Cameroon & 0.71 & 0.45 & 0.00 & 1.00 \\
\hline & Madagascar & 0.69 & 0.46 & 0.00 & 1.00 \\
\hline \multirow{5}{*}{$\begin{array}{l}\text { Type of rice }(\mathrm{TR}, \\
\text { Parboiled }=1, \\
\text { Nonparboiled }=0)\end{array}$} & Nigeria & 0.88 & 0.33 & 0.00 & 1.00 \\
\hline & Ghana & 0.40 & 0.49 & 0.00 & 1.00 \\
\hline & Cote d'Ivoire & 0.15 & 0.36 & 0.00 & 1.00 \\
\hline & Cameroon & 0.28 & 0.45 & 0.00 & 1.00 \\
\hline & Madagascar & - & - & - & - \\
\hline \multirow{5}{*}{$\begin{array}{l}\text { Origin of rice }(0, \\
\text { Imported }=1 \\
\text { Domestic }=0)\end{array}$} & Nigeria & 0.26 & 0.44 & 0.00 & 1.00 \\
\hline & Ghana & 0.71 & 0.46 & 0.00 & 1.00 \\
\hline & Cote d'Ivoire & 0.79 & 0.41 & 0.00 & 1.00 \\
\hline & Cameroon & 0.85 & 0.36 & 0.00 & 1.00 \\
\hline & Madagascar & 0.01 & 0.07 & 0.00 & 1.00 \\
\hline
\end{tabular}

Note: $\mathrm{N}=156$ for Nigeria, 204 for Ghana, 387 for Cote d'Ivoire, 305 for Cameroon and 182 for Madagascar.

A quality attribute that undoubtedly vertically differentiates rice is the level of impurities. If rice from the different countries was to sell at the same price, there would be consensus among African consumers that rice in the Cameroonian market is of the best quality, with impurities of only $0.26 \%$, followed by that in the Nigerian market (1.03\%). Rice in the Ghanaian market would generally be of the poorest quality. Interestingly, our statistics do not support the perception that imported rice, most of it from Asia, is of better quality relative to domestic rice, at least regarding the level of impurities. Rice in the Ghanaian market has the highest level of impurities, with $71 \%$ of the samples being of imported rice. In contrast, $74 \%$ of the samples from Nigeria are of domestic rice. Of course, it might well be that the few samples of Ghana's domestic rice were relatively highly contaminated. But it is also plausible that the relatively low level of impurities in rice in the Nigerian market is because of parboiling ${ }^{4}$, since Nigeria

\footnotetext{
${ }^{4}$ Parboiling of rice in Africa is most common in Nigeria. It is an additional step in the processing of paddy before milling. It involves steaming of the paddy to, among other things, increase milling recovery. The improved parboiling technologies being used such as the GEM technology require precleaning (winnowing and washing) of the paddy to remove impurities (Ndindeng et al., 2015).
} 
Table 3. Summary statistics for pooled data. $\mathrm{N}=1,234$

\begin{tabular}{|c|c|c|c|c|}
\hline Variable & Mean & Std. Dev & Min & Max \\
\hline Price (USD/kg) & 1.87 & 0.66 & 0.93 & 8.34 \\
\hline Impurities (\%) & 1.97 & 4.55 & 0.00 & 59.11 \\
\hline Head rice $(\%)$ & 84.20 & 17.21 & 1.96 & 99.98 \\
\hline Length-width ratio & 2.91 & 0.42 & 0.03 & 4.31 \\
\hline Chalkiness (\%) & 13.52 & 16.64 & 0.00 & 81.05 \\
\hline Lightness (\%) & 57.78 & 6.29 & -0.52 & 72.98 \\
\hline Amylose content (\%) & 24.19 & 2.30 & 12.73 & 32.11 \\
\hline Color intensity & 9.74 & 3.38 & 2.27 & 63.90 \\
\hline Peak viscosity (centipoise) & $1,572.72$ & 955.29 & 35.00 & $3,898.00$ \\
\hline Type of market (Urban $=1$, Rural $=0$ ) & 0.64 & 0.48 & 0.00 & 1.00 \\
\hline Type of rice $($ Parboiled $=1$, Nonparboiled $=0$ ) & 0.44 & 0.50 & 0.00 & 1.00 \\
\hline Origin of rice (Imported $=1$, Domestic $=0$ ) & 0.61 & 0.49 & 0.00 & 1.00 \\
\hline
\end{tabular}

has the highest percentage of parboiled rice (88\%). Notice the absence of parboiled rice among the samples obtained from the Malagasy market, as parboiled rice is hardly consumed in Eastern Africa. Unsurprisingly, the level of impurities is relatively high (3.64\%). Also, only $1 \%$ of samples are of imported rice.

The samples can also be analyzed in the context of the rice marketing standards for Africa. The five countries are members of the African Organisation for Standardisation (ARSO), which has developed and harmonized standards of several products for purposes of enhancing trade on the continent and increasing the competitiveness of the continent's products on the global market. ARSO has defined three grades of milled rice, namely, Grade 1, Grade 2, and Grade 3. In terms of head rice, rice from Nigeria, Ghana, and Cameroon meets the standard for Grade 2 rice (minimum of $80 \%$; the minimum for Grade 1 is $95 \%$ ), while that from Cote d'Ivoire and Madagascar meet the standard for Grade 3 rice (minimum of 65\%). However, if impurities-another critical attribute-is considered in addition to head rice, only Cameroonian rice would meet the standard for Grade 2 (maximum of $0.3 \%$; maximum for Grade 1 is $0.2 \%$ and that of Grade 3 is $0.6 \%$ ), and rice from the other countries would not meet the requirements for any grade.

It can be seen from Table 3 that most of the rice samples (61\%) are of imported rice as expected. Dependency on rice imports especially by West African countries has generally remained above $50 \%$ of the region's total rice supply over the last two decades (Tondel et al., 2020). Also, the samples generally have intermediate amylose content (20-25\%), with an average of $24.19 \%$. But some samples fall in the range of low (10-19\%) and others high ( $>25 \%)$ amylose content. The proportion of intact grains is an average of $84.20 \%$. The preferred commercial standard (Grade 1 ) is a minimum of $95 \%$ (or minimum of $5 \%$ broken).

\section{Empirical Approach}

\subsection{The Parametric Specification}

Parametric estimation of the hedonic price function in equation (1) requires that assumptions be made on $P(\cdot)^{\star}$. Most commonly, it is assumed that $P(\cdot)$ is a linear function of $X$ or a linear function of some power of $X$ (Anglin and Gençay, 1996). Thus,

$$
P=\beta X+e
$$

\footnotetext{
${ }^{*}$ This article has been updated since its original publication. See: https://doi.org/10.1017/aae.2022.10
} 
where $\beta$ is a vector of parameters and $e$ is the error term. Including an additive intercept in equation (5) would turn the coefficients into premiums or discounts over a base price defined by the intercept. In this study, we apply the semi-log (specifically the log-lin) functional form to our parametric specification and avoid the more flexible quadratic specifications that tend to be costly in terms of degrees of freedom, and whose interpretation is not straight-forward (Costanigro and McCluskey, 2011). In any case, most parametric specifications often involve logarithmic transformation of the dependent and/or independent variables to allow for linearity in parameters (Bin, 2000). Moreover, the fact that prices follow a lognormal rather than normal distribution implies nonnormality of disturbances, which would impede hypothesis testing in the case of a classical normal linear regression model. Also, the presence of dummy variables in our vector of regressors eliminates the option of a pure double log functional form. Thus, our log-lin model is the simplest parametric model that is most likely to account for nonlinear marginal effects with respect to rice prices (Haupt et al., 2010). Our estimable equation for all countries combined is:

$$
\begin{aligned}
\ln P= & \beta_{0}+\beta_{1} H R+\beta_{2} L W R+\beta_{3} C+\beta_{4} L+\beta_{5} C I+\beta_{6} A C+\beta_{7} P V+\beta_{8} I+\beta_{9} O+\beta_{10} T R \\
& +\beta_{11} T M+\beta_{12} C M R+\beta_{13} C I V+\beta_{14} G H A+\beta_{15} N I G+e
\end{aligned}
$$

where $\beta_{0}$ is the constant, $\beta_{1}, \ldots, \beta_{11}$ are coefficients on the quality attributes, HR is head rice, LWR is length-to-width ratio, $C$ is chalkiness, $L$ is lightness, $C I$ is color intensity, AC is amylose content, $\mathrm{PV}$ is peak viscosity, $I$ is impurities, $O$ is origin, TR is type of rice, TM is type of market, $\beta_{12}, \ldots, \beta_{15}$ are coefficients on country dummies (country fixed effects), and CMR, CIV, GHA, and NIG are Cameroon, Cote d'Ivoire, Ghana, and Nigeria, respectively. Madagascar is the reference country. We are particularly interested in testing the following hypotheses: $H_{0}: \beta_{1}=0$ versus $H_{A}: \beta_{1} \neq 0 ; H_{0}: \beta_{2}=0$ versus $H_{A}: \beta_{2} \neq 0 ; H_{0}: \beta_{3}=0$ versus $H_{A}: \beta_{3} \neq 0 ; H_{0}: \beta_{6}=0$ versus $H_{A}: \beta_{6} \neq 0 ; H_{0}: \beta_{8}=0$ versus $H_{A}: \beta_{8} \neq 0 ; H_{0}: \beta_{9}=0$ versus $H_{A}: \beta_{9} \neq 0 ; H_{0}: \beta_{10}=0$ versus $H_{A}: \beta_{10} \neq 0$; and $H_{0}: \beta_{11}=0$ versus $H_{A}: \beta_{11} \neq 0$. We hypothesize that consumers in SSA pay premiums for greater head rice, greater length-to-width ratio, domestic rice, parboiled rice, and rice sold in urban markets, and they discount chalkiness, high amylose content, and rice with a high proportion of impurities. Since the regressand is the natural log of prices, estimated coefficients would be interpreted as the relative (percentage) change in the price of rice due to a unit change in the explanatory variables. The hedonic price with respect to a continuous attribute is then obtained by multiplying the parameter estimate by the average market price, while that of a dummy attribute is calculated as $\left(e^{\beta}-1\right)$, and it is the effect on the price of rice of one category relative to another (Halvorsen and Palmquist, 1980). The nested model regression equation specification error test of Ramsey (1969) is applied to the empirical model to determine if any important nonlinearities may have been omitted.

\subsection{The Nonparametric Specification}

Because of the inherent nonlinearity of the hedonic price function and the uncertainty regarding its true functional form, it may have a nonadditive structure and can therefore be estimated nonparametrically, assuming that the observed and unobserved characteristics are independent (Bontemps et al., 2008). In a nonparametric regression, no assumptions are made about the structure of the model; the relationship between the dependent and predictor variables is completely data driven and is therefore not prone to misspecification error. The nonparametric form of the hedonic price model is:

$$
P=P(X)+e
$$

where the exact structure of $P(\cdot)$ is not specified. The regressors contained in $P(\cdot)$ are not the variables in the data per se but unknown functions of those variables. This is essentially the fully nonparametric 
model. It has relatively greater flexibility in selecting the appropriate functional form, but interpretation of its parameter estimates is difficult (Bin, 2000).

A common alternative to the fully nonparametric model is the additive nonparametric model (Bontemps et al., 2008; Hastie and Tibshirani, 1986). In this model,

$$
P(X)=P\left(x_{1}, \ldots \ldots \ldots, x_{n}\right)=c+\sum_{n=1}^{N} g_{n}\left(x_{n}\right)
$$

where $c$ is a constant, $x_{i}$ is the amount of characteristic $i$ contained in one unit of the good, and $n=1, \ldots \ldots N$, is a set of $N$ unknown smooth functions satisfying the identifiability condition that $E\left[g_{n}\left(x_{n}\right)\right]=0$ for every $n$. The empirical model is specified as:

$$
P=c+\sum_{n=1}^{N} g_{n}\left(x_{n}\right)+e
$$

Comparing two or more models requires the regressand to be the same. Therefore, the nonparametric model in equation (9) is estimated with the natural log of prices as the regressand. The additive structure enables the identification of the effect of an individual regressor on the regressand, ceteris paribus. And unlike the fully nonparametric model, it does not greatly suffer from slow rates of convergence and hence the curse of dimensionality. In estimating equation (9), we do not interact the regressors to further mitigate the curse of dimensionality. Hence, the estimated model can be interpreted in much the same way as our parametric log-lin model (Bin, 2000; Eubank, 1999, p.72; Hastie and Tibshirani, 2014). The estimates obtained are average marginal effects that measure the relative change in the price of rice for instantaneous absolute changes in the levels of attributes. Drawing upon Bontemps et al. (2008), hedonic prices for continuous attributes are calculated by multiplying the sample average of rice prices by the average marginal effects. Those of discrete attributes are calculated as in the parametric model but with average marginal effects as exponents.

The most common nonparametric regression estimators are the kernel regression estimators and series regression estimators. Given our uncertainty about the appropriate bandwidth for a kernel regression, we employ a series regression, and specifically one that uses the B-spline basis, since B-splines provide a better approximation of the mean function than polynomial and natural spline bases (StataCorp, 2019).

To choose between the parametric and nonparametric model, we follow Wooldridge (1992), who proposes a test against nonparametric alternatives. His test essentially builds on the Davidson-MacKinnon $J$ test of nonnested models (Davidson and MacKinnon, 1981). The nonparametric model should not nest the parametric model and care should be taken not to overfit the former. The test involves adding fitted values from the nonparametric regression as a variable in the linear parametric regression model and performing a $t$-test on the fitted values variable. The fitted values represent the influence of variables not included in the parametric model. If the coefficient on this additional regressor is not statistically significant, we can accept the parametric model as the true model because the fitted values do not have additional explanatory power beyond that contributed by variables in the parametric model. In other words, the parametric model encompasses the nonparametric model in the sense that the latter does not contain any additional information that will improve the performance of the former. An empirical application of this test can be found in Anglin and Gençay (1996).

\subsection{Returns to Quality Upgrading}

Returns to quality upgrading are estimated using a partial equilibrium model. Quality upgrading causes a rightward shift in the demand curve. Assuming, for each country, linear demand and supply curves, perfectly elastic supply of nonfarm inputs and marketing services and no substitution between farm product and marketing services, Voon and Edwards (1991) show that changes in economic surpluses due to quality improvement are as follows: 


$$
\begin{gathered}
T S=0.5 k P_{0} Q_{0}(2+\varepsilon Z) \\
P S=0.5 P_{0} Q_{0}\left(2 Z+\varepsilon Z^{2}\right) \\
C S=T S-P S
\end{gathered}
$$

where TS, PS, and CS are changes in total surplus, producer surplus and consumer surplus, respectively, $P_{0}$ and $Q_{0}$ are initial equilibrium retail prices and quantities, respectively, $\varepsilon$ is the supply elasticity at the initial equilibrium, $Z=k \eta /(\varepsilon+\eta)$ where $\eta$ is the demand elasticity at the initial equilibrium, and $k$ is the proportionate vertical shift in demand for rice following quality improvement. It is calculated as:

$$
k=\left(\sum_{i=1}^{n} p_{i}\left(x_{i}^{*}-x_{i}\right)\right) / P_{0}
$$

where $p_{i}$ is the hedonic price of attribute $i, x_{i}$ is the original quantity of the attribute and $x_{i}^{*}$ is the quantity of the attribute after quality improvement. While economic surpluses are calculated for each country, the BCR and IRR are calculated for all countries combined because of the difficulty in separating investment costs per country.

\section{Results}

The parametric model was subjected to diagnostic tests for normality of residuals, multicollinearity, heteroscedasticity, and specification error. The Anderson-Darling test of normality produced a test statistic of 20.24 with a $p$-value of 13.69. Therefore, we do not reject the null hypothesis that the residuals from our model are normally distributed. Variance-inflating factors were used to check for multicollinearity, and it was found to be negligible, with values less than 10 . We test for the null hypothesis of homoskedasticity, first with the Breusch-Pagan-Godfrey test (Breusch and Pagan, 1979; Godfrey, 1978), which is sensitive to the normality of errors assumption, and with White's general test (White, 1980), which does not assume normality. In both tests, we reject the null hypothesis of homoskedasticity at the $1 \%$ level of significance with chi-squared values of 274.40 and 574.32, respectively. Consequently, we estimate a log-lin model with White's heteroscedasticity-corrected standard errors.

Ordinary least squares regression results of the parametric hedonic price model are summarized in Table 4 . They are generally consistent with observed preferences of rice consumers in parts of SSA. However, the model fails the regression specification error test; with an Fstatistic of 48.38 , we reject, at the $1 \%$ level of significance, the null hypothesis that the model is correctly specified. This points to the possibility that significant nonlinearities have not been accounted for in our parametric specification. To implement Wooldridge's (1992) test of the nonparametric alternative, the nonparametric model is estimated with the same variables except lightness, to ensure it does not nest the parametric model ${ }^{5}$. The test yields a $t$-statistic of 8.36 on the fitted values of the nonparametric model, with a $p$-value $=0.000$. Therefore, the data suggest that the nonparametric model provides a better fit of the hedonic price mean function.

Results of the nonparametric model are presented in Table 5 along with computed hedonic prices of the statistically significant quality attributes. Consumers in the five countries show significant preference for rice with a high proportion of intact grains, slender grains, and greater peak viscosity, although the implicit price of peak viscosity is very small $(0.02 \$ / \mathrm{kg})$. A $1 \%$ increase in the proportion of intact grains increases the price of rice by $1 \$$ on average. The positive and significant average marginal effect of head rice is to be expected since head rice is one of the key attributes

\footnotetext{
${ }^{5}$ We performed robustness checks by excluding other variables, at least one at a time. In all cases, the nonparametric model was the better model. However, excluding the variable "lightness" provided the best fit to the data.
} 
Table 4. OLS regression results of the parametric hedonic price model for Cameroon, Cote d'Ivoire, Ghana, Nigeria, and Madagascar

\begin{tabular}{|c|c|c|c|}
\hline Variable & Coefficient & $t$-statistic & $p$-value \\
\hline Head rice & $0.005(0.0007)$ & 6.49 & 0.000 \\
\hline Length-width ratio & $0.14(0.37)$ & 3.76 & 0.000 \\
\hline Chalkiness & $-0.004(0.0006)$ & -5.51 & 0.000 \\
\hline Lightness & $0.005(0.002)$ & 2.41 & 0.016 \\
\hline Color intensity & $0.007(0.003)$ & 2.60 & 0.009 \\
\hline Amylose content & $-0.02(0.003)$ & -7.47 & 0.000 \\
\hline Peak viscosity & $0.0001(0.00002)$ & 7.48 & 0.000 \\
\hline Impurities & $-0.008(0.002)$ & -4.49 & 0.000 \\
\hline Origin & $-0.01(0.02)$ & -0.47 & 0.639 \\
\hline Type of rice & $0.10(0.03)$ & 3.78 & 0.000 \\
\hline Type of market & $0.07(0.01)$ & 5.50 & 0.000 \\
\hline Cameroon & $0.29(0.05)$ & 5.87 & 0.000 \\
\hline Cote d'Ivoire & $0.19(0.03)$ & 5.62 & 0.000 \\
\hline Ghana & $0.37(0.04)$ & 8.71 & 0.000 \\
\hline Nigeria & $0.32(0.05)$ & 5.84 & 0.000 \\
\hline Constant & $-0.40(0.23)$ & -1.74 & 0.082 \\
\hline $\begin{array}{l}\mathrm{N}=1,012 \\
F(15,996)=40.72 \\
\text { Prob }>F=0.000 \\
R \text {-squared }=0.46 \\
\text { RMSE }=0.20\end{array}$ & & & \\
\hline
\end{tabular}

Note: Dependent variable is natural log of rice prices. Figures in parentheses are robust standard errors.

with a bearing on formal quality grades, which transmit quality information to consumers. Rice grades in the five countries include Premium, Grade 1, Grade 2, and Grade 3, with head rice and hence quality declining from Premium to Grade $3^{6}$. Head rice depends on intrinsic varietal properties and postharvest operations. Ndindeng et al. (2021a) have established that farmers' traditional methods of harvesting, threshing, and drying reduce head rice by $8.5 \%, 5 \%$, and $13.3 \%$, respectively, relative to modern methods. They also find NERICA-L-19 to yield greater head rice than TOX3145.

Consumers also prefer rice with slender grains, parboiled to nonparboiled rice, and rice sold in urban markets to that sold in rural markets. Slenderness of grains attracts the largest premium of $45 \$ / \mathrm{kg}$. For categorical variables, the estimates are differences rather than derivatives. For instance, if all rice on the market were to be parboiled rice, the price of rice would be $10 \$$ more than if all the rice were nonparboiled. Likewise, if all rice were to be sold in urban markets, the price would be $6 \$$ more than if all of it were sold in rural markets. Preference for parboiled rice has been observed in Benin (Naseem et al., 2013), and therefore, parboiling of rice using improved technology is seen as a viable means to increasing the competitiveness of domestic rice value

\footnotetext{
${ }^{6}$ This is the case in most of SSA except in Senegal where preference for broken rice is very strong (Demont et al., 2013a; Rutsaert et al., 2009).
} 
Table 5. Regression results of the nonparametric hedonic price model for Cameroon, Cote d'Ivoire, Ghana, Nigeria, and Madagascar

\begin{tabular}{|c|c|c|c|c|}
\hline Variable & Av. Marginal Effect & z-statistic & $p$-value & Hedonic Price $(\$ / \mathrm{kg})$ \\
\hline Head rice & $0.008(0.005)$ & 1.70 & 0.090 & 0.01 \\
\hline Length-width ratio & $0.24(0.04)$ & 6.52 & 0.000 & 0.45 \\
\hline Chalkiness & $0.001(0.006)$ & 0.18 & 0.857 & \\
\hline Color intensity & $0.008(0.006)$ & 1.38 & 0.168 & \\
\hline Amylose content & $-0.04(0.004)$ & -8.25 & 0.000 & -0.07 \\
\hline Peak viscosity & $0.0001(0.00002)$ & 4.32 & 0.000 & 0.0002 \\
\hline Impurities & $-0.11(0.04)$ & -3.06 & 0.002 & -0.21 \\
\hline Origin & $-0.05(0.02)$ & -2.17 & 0.030 & -0.05 \\
\hline Type of rice & $0.10(0.03)$ & 3.08 & 0.002 & 0.10 \\
\hline Type of market & $0.06(0.01)$ & 4.69 & 0.000 & 0.06 \\
\hline Cameroon & $0.33(0.05)$ & 6.93 & 0.000 & \\
\hline Cote d'Ivoire & $0.22(0.04)$ & 5.68 & 0.000 & \\
\hline Ghana & $0.48(0.04)$ & 10.58 & 0.000 & \\
\hline Nigeria & $0.28(0.05)$ & 5.79 & 0.000 & \\
\hline
\end{tabular}

Note: Dependent variable is natural log of rice prices. Figures in parentheses are robust standard errors. $\mathrm{N}=1,012$.

chains (Akoa Etoa et al., 2016). Similarly, consumer preference for rice sold in urban markets to that sold in rural ones has been observed for two classes of consumers in the Beninese market (Ndindeng et al., 2021b).

The results reveal negative implicit prices for impurities, amylose content, and imported rice. In fact, impurities are found to be the most important negative attribute of rice; the average marginal effect of -0.11 translates into a marginal implicit price of $-0.21 \mathrm{USD} / \mathrm{kg}$. The finding regarding amylose content implies that consumers generally discount rice that does not become sticky and tender when cooked. Despite most samples being of intermediate amylose content, it appears consumers would want to see further reduction in the level of this attribute.

The finding that consumers discount imported rice is contrary to most commentary in the literature (see, for instance, Fiamohe et al., 2015; Demont et al., 2017, 2013b; Demont and Ndour, 2015). The mean market price of imported rice is significantly higher than that of locally produced rice (i.e., $\$ 2.00$ vs. $\$ 1.68$ per $\mathrm{kg} ; t=-8.37, p=0.000$ for a $t$-test of the difference in means). But from our regression model, if all rice on the market were to be imported, the price would be $5 \Phi$ less than what it would be if all rice were locally produced. We conjecture that improvement in rice yields, and to some extent quality, that has been witnessed in SSA over the last two decades may have led to a gradual shift of preferences away from imported to domestic rice ${ }^{7}$. Indeed, Demont et al. (2013a) and Fiamohe et al. (2015) found that consumers were willing to pay substantial price premiums for domestic rice in Senegal and Togo, respectively.

\footnotetext{
${ }^{7}$ There are two possible explanations as to why consumers discount imported rice: (a) it may not necessarily be the case that imported rice is of poorer quality than domestic rice. Rather, it could simply be that it does not have the right quantities of the attributes they like. In a previous analysis of data (like the one used in this study) for a different West African country, we compared imported with domestic rice and found imported rice to have significantly more amylose content. We then found a considerable proportion of consumers to highly discount amylose content as is the case in this study; (b) consumers' preference for domestic rice to imported rice might arise from sheer ethnocentric tendencies. It would have been informative to interact some quality attributes with origin (and market type), but this would have made the nonparametric model difficult to estimate because of the "curse of dimensionality."
} 


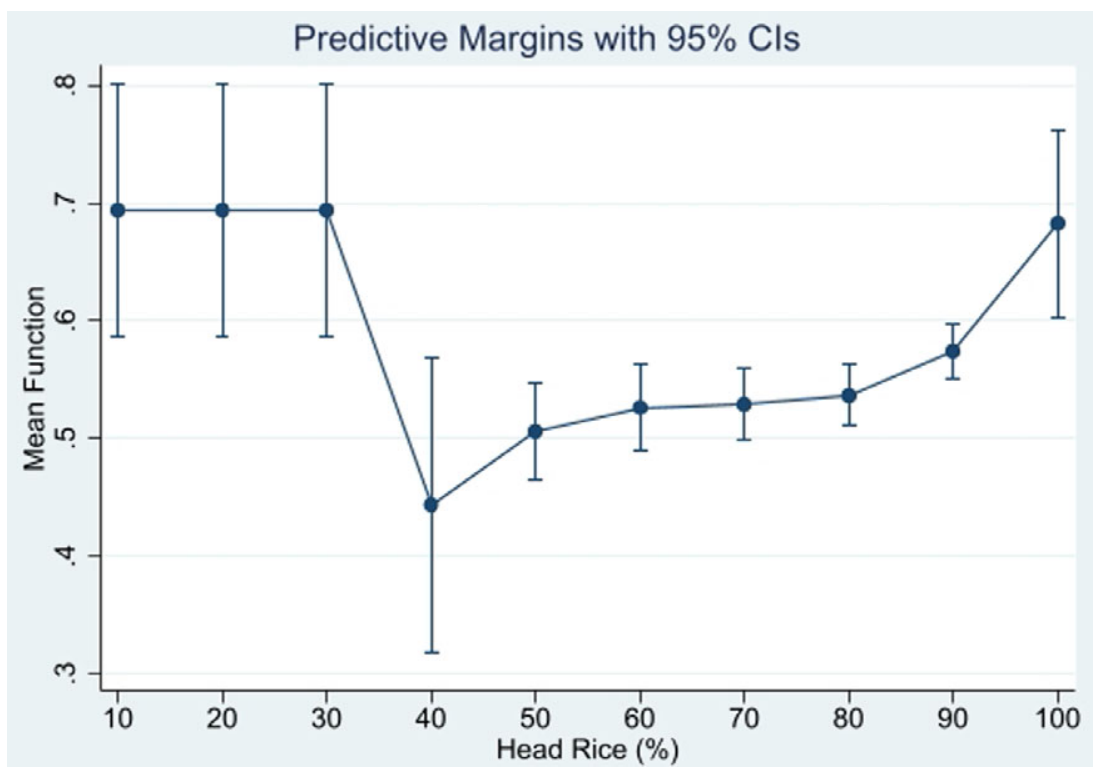

Figure 1. Predictive margins for head rice

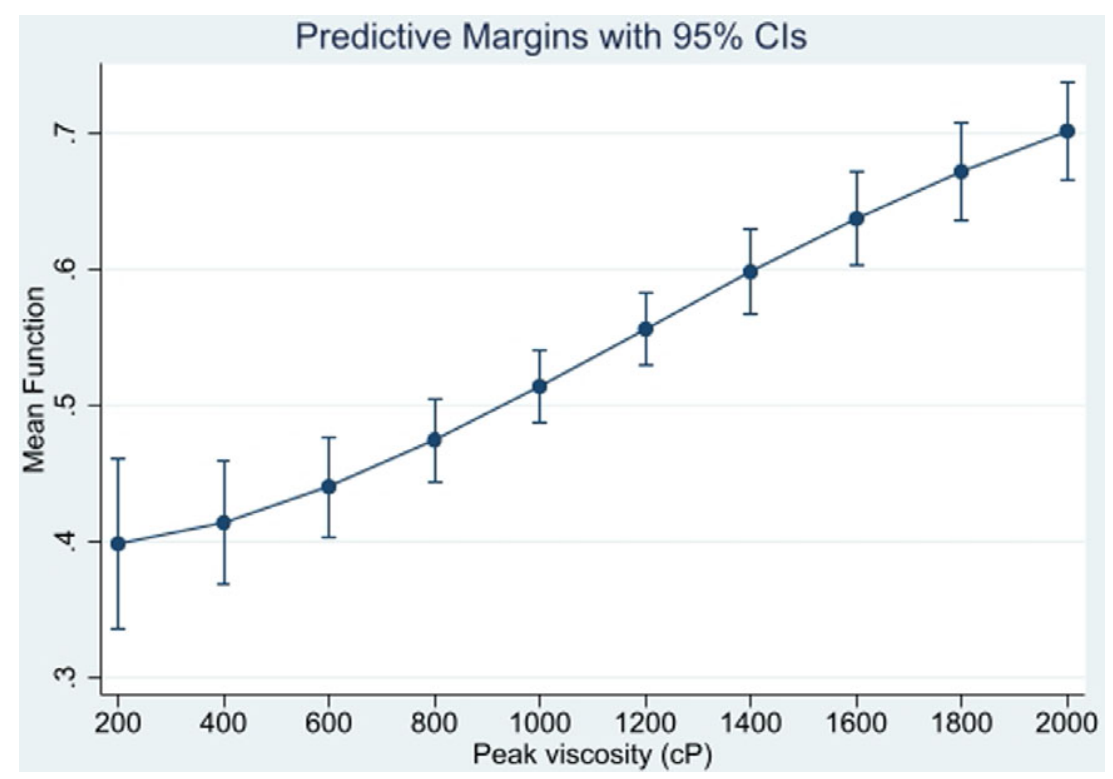

Figure 2. Predictive margins for peak viscosity

Estimation of the nonparametric model was premised on the presence of nonlinearities in the hedonic price function. We further examine the nonlinearities through graphical analysis, focusing on the statistically significant continuous variables. Figures 1-5 show predictive margins for head rice, peak viscosity, amylose content, impurities, and length-to-width ratio with $95 \%$ confidence intervals. We observe nonlinearities in the mean function with respect to all variables except peak viscosity. Therefore, a nonparametric specification appears to be a more reasonable approach to accounting for complex nonlinearities in the hedonic price model of rice attributes in SSA. 


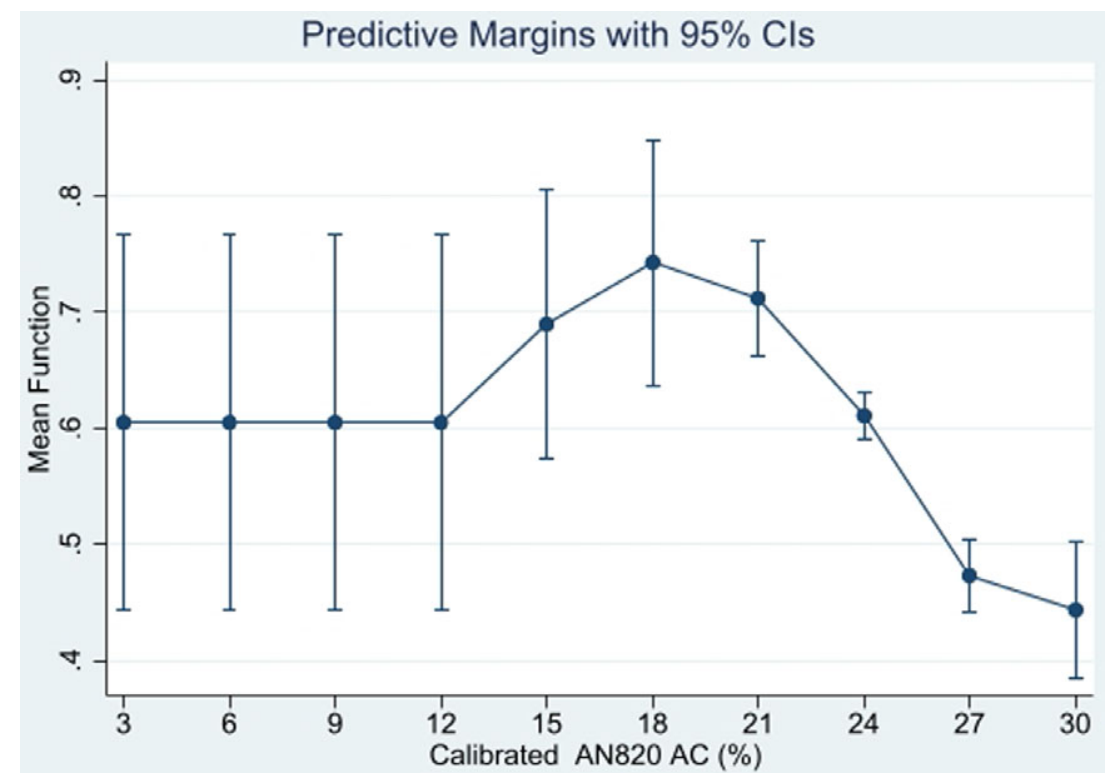

Figure 3. Predictive margins for amylose content

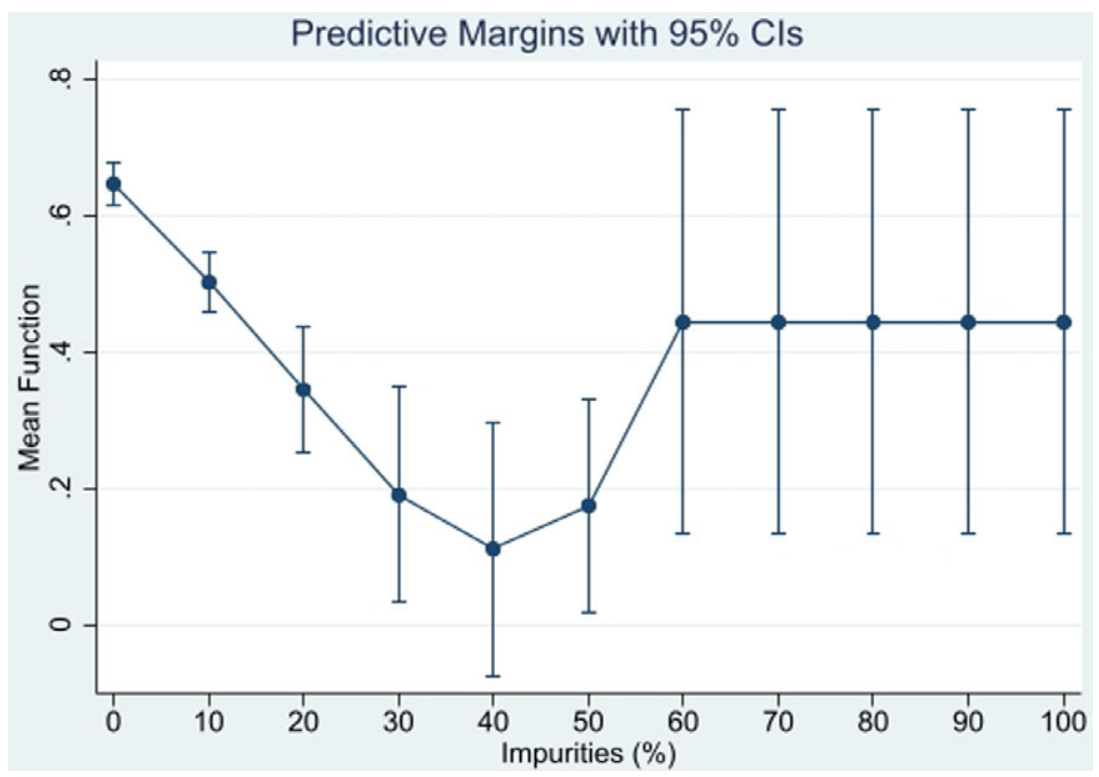

Figure 4. Predictive margins for impurities

To determine the payoff from quality improvement, we consider a reduction in amylose content from each country's mean value to at least the Premium grade's $19 \%$ as recommended by Ndindeng et al. (2020). We consider amylose content only because it is the only intrinsic attribute that was discounted by consumers and for which an improvement can be achieved through breeding. Parameters used to calculate returns to quality improvement and their sources are provided in Table 6. Despite a reduction in producer surplus in Ghana and a reduction in consumer surplus in all countries except Ghana, all countries register an increase in total surplus following a reduction 


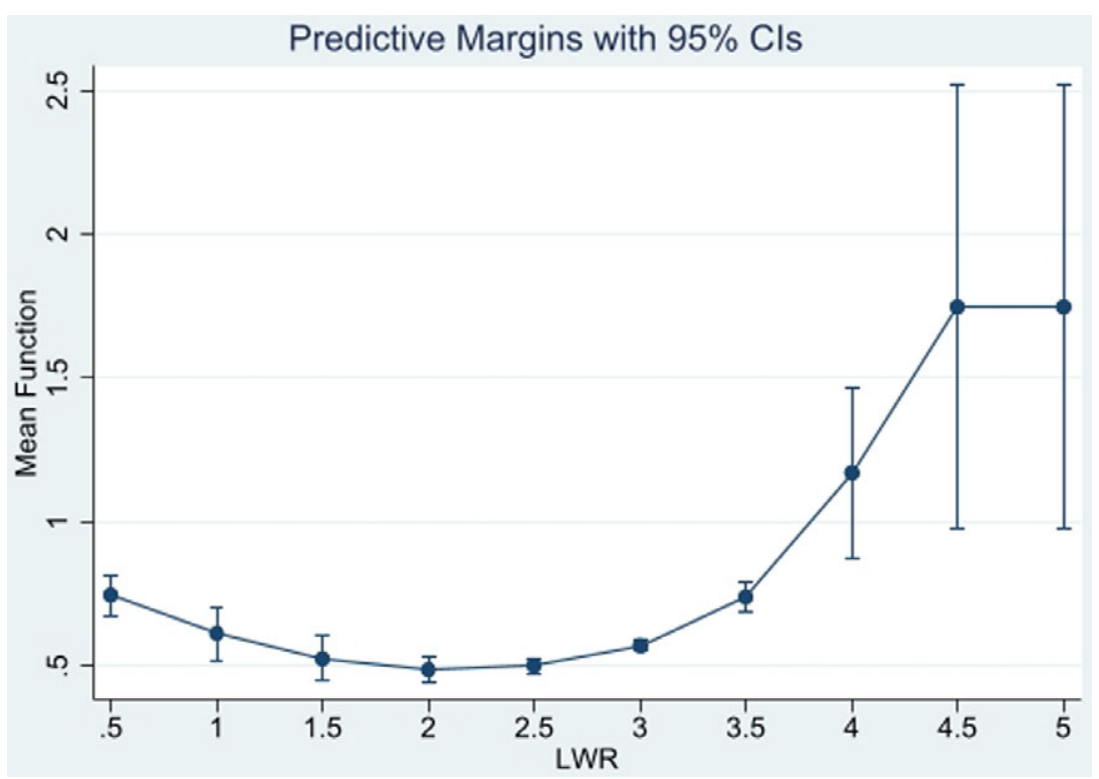

Figure 5. Predictive margins for length-to-width ratio

Table 6. Parameters used in calculating returns to quality improvement

\begin{tabular}{|c|c|c|c|c|c|}
\hline Parameter & Cote d'Ivoire & Nigeria & Ghana & Cameroon & Madagascar \\
\hline$P_{0}(\$ / \mathrm{kg})$ & 1.74 & 1.86 & 2.25 & 1.99 & 1.52 \\
\hline$Q_{0}(k g)^{a}$ & $412,500,000$ & $2,540,160,000$ & $312,660,000$ & $119,830,000$ & $946,176,000$ \\
\hline$\varepsilon$ & 0.60 & 0.60 & 0.60 & 0.60 & 0.20 \\
\hline$\eta$ & -1.03 & -1.64 & -0.20 & -0.90 & -0.62 \\
\hline$p(\$ / \mathrm{kg})$ & -0.07 & -0.07 & -0.07 & -0.07 & -0.07 \\
\hline$x(\%)$ & 23.91 & 24.19 & 24.22 & 24.78 & 23.68 \\
\hline$x^{*}(\%)$ & 19.00 & 19.00 & 19.00 & 19.00 & 19.00 \\
\hline$k$ & 0.20 & 0.20 & 0.16 & 0.20 & 0.22 \\
\hline$Z$ & 0.47 & 1.26 & -0.08 & 0.61 & 0.32 \\
\hline
\end{tabular}

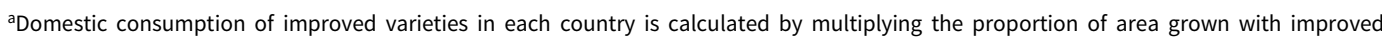
varieties by the country's total domestic production. Data on area under improved varieties are from the Agricultural Science and Technology Indicators (ASTI) (2021) database, while data on total production are from the United States Department of Agriculture (USDA). (2020).

$\varepsilon$ : Magrini et al. (2017) for Cote d'Ivoire, Nigeria, Ghana, and Cameroon; Dorosh and Minten (2005) for Madagascar.

$\eta$ : Average of standard and local rice market elasticities in Coulibaly et al. (2015) for Cote d'Ivoire; average of elasticities for local, imported, and dining out rice in Gyimah-Brempong and Kuku-Shittu (2016) for Nigeria; Kotchofa (2018) for Ghana; average of urban and rural elasticities for cereals in Kane et al. (2015) for Cameroon; Tollens (2007) for Madagascar.

$p, x, k$, and $Z$ are from authors' own calculations.

in amylose content (Table 7). As expected, the largest net welfare gain of over 1.2 billion dollars annually is in Africa's most populous and largest rice-consuming country, Nigeria, followed by Madagascar at $\$ 319.83$ million. The combined net welfare gain for all countries is $\$ 1.92$ billion.

To calculate the BCR and IRR, we need estimates of the costs of varietal development and dissemination. We use figures provided by Diagne et al. (2012) for the GRiSP budget for Africa for the period 2011-2020 to roughly estimate average and total costs for the five countries 
Table 7. Payoff to reduction in amylose content

\begin{tabular}{lcccccc}
\hline Measure & Cote d'Ivoire & Nigeria & Ghana & Cameroon & Madagascar & Total \\
\hline PS(\$/annum) & $387,808,628$ & $8,209,359,559$ & $-55,731,466$ & $172,064,748$ & $472,128,687$ & $9,185,630,156$ \\
\hline CS (\$/annum) & $-225,907,939$ & $-6,937,486,951$ & $167,194,398$ & $-114,709,832$ & $-152,299,576$ & $-7,263,209,900$ \\
\hline TS (\$/annum) & $161,900,689$ & $1,271,872,608$ & $111,462,932$ & $57,354,916$ & $319,829,111$ & $1,922,420,256$ \\
\hdashline BCR & & & & & & 47.86 \\
\hline IRR & & & & & $90 \%$ \\
\hline
\end{tabular}

in this study. It is assumed that these costs are incurred in a period of 10 years, but benefits would start in the eighth year and last for at least 14 years. A discount rate of $12 \%$, typical of World Bank investment appraisals, is applied (Bonzanigo and Kalra, 2014).

A BCR of 47.86 and an IRR of $90 \%$ are obtained. Thus, efforts to upgrade the quality of rice by lowering amylose content would be of great benefit to SSA. In studies listed in Tollens et al. (2013), internal rates of return to rice genetic improvement in SSA range from 18\% to 182\%. Diagne et al. (2012) obtained an IRR of $84 \%$ for rice research in Africa. More recently, an average BCR of 34.30 for investment in rice R\&D has been documented by Alston et al. (2020). Our analysis of the IRR has one major limitation: the IRR obtained is the financial rate of return, which is based on observed prices. Because of lack of information on the likely price distortions over time and potential externalities from investing in rice research, we are unable to adjust the IRR to obtain the economic rate of return. Therefore, we have essentially calculated the upper bound of the IRR.

\section{Summary and Concluding Remarks}

The study estimates implicit marginal prices of rice quality attributes using data obtained from five countries in SSA. In doing so, it addresses an important but rather neglected issue in the empirical estimation of hedonic price functions of food products - the choice between parametric and non/ semiparametric methods. It then applies a partial equilibrium model to determine the payoff to investing in grain quality improvement. The study finds the additive nonparametric model to be superior to the parametric specification. Results of the nonparametric model indicate that rice consumers have strong preferences for head rice, slender grains, peak viscosity, parboiled rice, and rice sold in urban markets. However, they discount impurities, amylose content and imported rice. Graphical inspection of predicted margins confirms the existence of nonlinearities in the mean function with respect to at least head rice, impurities, length-to-width ratio, and amylose content. A reduction in amylose content is found to yield considerably large net economic benefits.

The results have important implications for upgrading rice value chains in SSA and are especially timely because of current efforts by CGIAR and partners to develop product profiles to enable replacement of commercially dominant rice varieties in Africa (CGIAR Excellence in Breeding Platform, 2020). Breeding programs should aim to increase head rice, length-to-width ratio, and peak viscosity, while reducing amylose content. Also, value chain development efforts dealing with postharvest handling and value addition should promote practices such as parboiling, and interventions that reduce impurities and increase head rice.

Given the paucity of empirical work involving nonparametric hedonic price models of food products, our results suggest that economists ought to do more to explore the use of nonparametric models in this type of analysis. However, we are cautious not to infer broadly that nonparametric models are superior to parametric ones. As observed by Eubank (1999), a nonparametric model can be used to justify the use of a parametric model, and therefore, using one model does not necessarily disqualify the other. For future research, we recommend integrating issues of buyer-seller information asymmetry and the resulting bargaining power in analyzing shadow prices of rice quality attributes in SSA. Rosen's (1974) hedonic price model assumes a 
competitive market equilibrium. In essence, such a study would be testing this assumption for the case of rice retail markets in SSA.

Acknowledgements. We are grateful to Erasmus Tang, Abubakar Bunza, Elvis Baidoo, Ahmed Dembele, Ghyslain Kouadio, Irina Andrianina, and Aubert Razafimbazaha for their assistance in rice sample collection.

Competing Interests. Edgar Twine, Sali Ndindeng, Gaudiose Mujawamariya, and Koichi Futakuchi declare none.

Data Availability Statement. The data that support the findings of this study are available from the corresponding author, EET, upon reasonable request.

Funding Statement. This work was supported by the Department of Foreign Affairs, Trade and Development of the Government of Canada (Grant No. A034968); the Transforming Irrigation Management in Nigeria (TRIMING) project financed by the World Bank (and implemented by the Federal Ministry of Water Resources); the African Development Bank (Grant No. 2100155022217); and the CGIAR Research Program on Rice Agri-Food Systems.

Author Contributions. Conceptualization, E.E.T and S.A.N; Methodology, E.E.T and S.A.N; Formal Analysis, E.E.T and S.A.N; Data Curation, S.A.N and G.M; Writing - Original Draft, E.E.T; Writing - Reviewing and Editing, E.E.T, S.A.N, and G.M; Supervision, K.F; Funding Acquisition, K.F.

\section{References}

Abansi, C.L., B. Duff, and B.O. Juliano. "Consumer Demand for Rice Grain Quality in Selected Rural and Urban Markets in the Philippines.” Consumer Demand for Rice Grain Quality. M.C.S. Unnevehr, L.J. B. Duff, and B.O. Juliano, eds. Manila and Ottawa: IRRI and IDRC, 1992.

Adejumo-Ayibiowu, D. Mapping of Poverty Reduction Strategies Papers (PRSP), Sector Strategies and Policies related to Rice Development in Nigeria. Coalition for African Rice Development (CARD), 2010. Internet site: http://riceforafrica.net/ images/card_photos/ifad_nigeria.pdf

Agricultural Science and Technology Indicators (ASTI). A Consolidated Database of Crop Varietal Releases, Adoption, and Research Capacity in Africa South of the Sahara. CGIAR's DIIVA Project, IFPRI. 2021. Internet site: https://www.asti.cgiar. org/diiva\# 1

Akoa Etoa, J.M., S.A. Ndindeng, E.S. Owusu, N. Woin, B. Bindzi, and M. Demont. “Consumer Valuation of an Improved Rice Parboiling Technology: Experimental Evidence from Cameroon.” African Journal of Agricultural and Resource Economics 11(2016):8-21.

Alston, J.M., P.G. Pardey, and X. Rao. The Payoff to Investing in CGIAR Research. SoAR Foundation, 2020. Arlington, VA, USA.

Anglin, P.M., and R. Gençay. "Semiparametric Estimation of a Hedonic Price Function." Journal of Applied Econometrics 11(1996):633-48.

Bao, H.X.H., and A.T.K. Wan. "On the Use of Spline Smoothing in Estimating Hedonic Price Models: Empirical Evidence using Hong Kong Data." Real Estate Economics 32(2004):487-507.

Beintema, N., A.M. Nasir, and L. Gao. Agricultural R\&D Indicators Factsheet: Nigeria. Agricultural Science and Technology Indicators (ASTI), IFPRI, Washington, DC. 2017

Bin, O. "Estimation of Implicit Prices in Hedonic Price Models: Flexible Parametric versus Additive Nonparametric Approach.” Ph.D. dissertation, Oregon State University, 2000.

Bonanno, A., F. Bimbo, M. Costanigro, A.O. Lansink, and R. Viscecchia. "Credence Attributes and the Quest for a Higher Price - A Hedonic Stochastic Frontier Approach.” European Review of Agricultural Economics 46(2019):163-92.

Bontemps, C., M. Simioni, and Y. Surry. "Semiparametric Hedonic Price Models: Assessing the Effects of Agricultural Nonpoint Source Pollution." Journal of Applied Econometrics 23(2008):825-42.

Bonzanigo, L., and N. Kalra. "Making Informed Investment Decisions in an Uncertain World.” Policy Research Working Paper 6765, World Bank, 2014.

Breusch, T., and A. Pagan. "A Simple Test for Heteroscedasticity and Random Coefficient Variation." Econometrica 47(1979):1287-94.

Cadoni, P., and F. Angelucci. "Analysis of Incentives and Disincentives for Rice in Nigeria." MAFAP Technical Notes Series, FAO, 2013.

CGIAR Excellence in Breeding Platform - New Project Aims to Modernize Rice Breeding in Africa, 2020. Internet site: https://excellenceinbreeding.org/blog/new-project-aims-modernize-rice-breeding-africa (Accessed December 2, 2020).

Costanigro, M., and J.J. McCluskey. "Hedonic Price Analysis in Food Markets." The Oxford Handbook of the Economics of Food Consumption and Policy. J.L. Lusk, J. Roosen, and J.F. Shogren, eds. Oxford, U.K.: Oxford University Press, 2011.

Costanigro, M., R.C. Mittelhammer, and J.J. McCluskey. "Estimating Class-Specific Parametric Models Under Class Uncertainty: Local Polynomial Regression Clustering in an Hedonic Analysis of Wine Markets." Journal of Applied Econometrics 24(2009):1117-35. 
Coulibaly, J.Y., N. Tebila, and A. Diagne. "Reducing Rice Imports in Cote d'Ivoire: Is a Rise in Import Tariff the Solution?" Agricultural and Resource Economics Review 44(2015):195-213.

Coulson, N.E. "Semiparametric Estimates of the Marginal Price of Floorspace." Journal of Real Estate Finance and Economics 5(1992):73-83.

Cropper, M.L., L.B. Deck, and K.E. McConnell. “On the Choice of Functional Form for Hedonic Price Functions.” Review of Economics and Statistics 70(1988):668-75.

Cuevas, R.P., V.O. Pede, J. McKinley, O. Velarde, and M. Demont. "Rice Grain Quality and Consumer Preferences: A Case Study of Two Rural Towns in the Philippines." PLoS ONE 11(2016): e0150345.

Dalton, T.J., and R.G. Guei. "Productivity Gains from Rice Genetic Enhancements in West Africa: Countries and Ecologies." World Development 31(2003):359-74.

Davidson, R., and J.G. MacKinnon. "Several Tests for Model Specification in the Presence of Alternative Hypotheses." Econometrica 49(1981):781-93.

Demont, M., R. Fiamohe, and A.T. Kinkpe. "Comparative Advantage in Demand and the Development of Rice Value Chains in West Africa." World Development 96(2017): 578-90.

Demont, M., and M. Ndour. "Upgrading Rice Value Chains: Experimental Evidence from 11 African Markets." Global Food Security 5(2015):70-76.

Demont, M., P. Rutsaert, M. Ndour, and W. Verbeke. "Reversing Urban Bias in African Rice Markets: Evidence from Senegal." World Development 45(2013a):63-74.

Demont, M., P. Rutsaert, M. Ndour, W. Verbeke, P.A. Seck, and E. Tollens. "Experimental Auctions, Collective Induction and Choice Shift: Willingness-To-Pay for Rice Quality in Senegal.” European Review of Agricultural Economics 40(2013b):261-86.

Diagne, A., D.Y. Alia, M.C.S. Wopereis, and K. Saito. "Impact of Rice Research on Income and Poverty in Africa: An Exante Analysis." Selected Paper Prepared for Presentation at the International Association of Agricultural Economists (IAAE) Triennial Conference, Foz do Iguaçu, Brazil, August 18-24, 2012.

Domgho, L.V.M., D. Begoude, T.P. Ngome, and G-J. Stads. Fiche d'information sur les indicateurs de la R\&D agricole: Cameroun. Agricultural Science and Technology Indicators (ASTI), IFPRI, Washington, DC, $2018 \mathrm{~b}$.

Domgho, L.V.M., R. Randriamanamisa, and G-J. Stads. Fiche d'information sur les indicateurs de la RßD agricole: Madagascar. Agricultural Science and Technology Indicators (ASTI), IFPRI, Washington, DC, 2018c.

Domgho, L.V.M., S. Doumbia, and G-J. Stads. Fiche d'information sur les indicateurs de la R\&D agricole: Cote d'Ivoire. Agricultural Science and Technology Indicators (ASTI), IFPRI, Washington, DC, 2018a.

Dorosh, P.A., and B. Minten. "Rice Price Stabilization in Madagascar: Price and Welfare Implications of Variable Tariffs." Working Paper No. 192, Cornell Food and Nutrition Policy Program, 2005.

Erenstein, O., F. Lançon, O. Osiname, and M. Kebbeh. Operationalising the Strategic Framework for Rice Sector Revitalisation in Nigeria. Project Report - The Nigerian Rice Economy in a Competitive World: Constraints, Opportunities and Strategic Choices. Africa Rice Center, Abidjan, Cote d'Ivoire, 2004.

Espinosa, J.A., and B.K. Goodwin. "Hedonic Price Estimation for Kansas Wheat Characteristics." Western Journal of Agricultural Economics 16(1991):72-85.

Essegbey, G.O., and R. Asare. Assessment of Agricultural Research Capacities in Ghana: The Case of Council for Scientific and Industrial Research (CSIR). ASTI/IFPRI-CORAF/WECARD Project Report. 2014. Internet site: http://ebrary.ifpri. org/cdm/ref/collection/p15738coll2/id/128689

Eubank, R.L. Nonparametric Regression and Spline Smoothing. New York and Basel: Marcel Dekker, Inc., 1999.

Falck-Zepeda, J., P. Zambrano, J.I. Cohen, O. Borges, E.P. Guimarães, D. Hautea, J. Kengue, and J. Songa. "Plant Genetic Resources for Agriculture, Plant Breeding, and Biotechnology: Experiences from Cameroon, Kenya, the Philippines, and Venezuela.” Discussion Paper 00762. IFPRI, Washington, DC, 2008.

Fiamohe, R., T. Nakelse, A. Diagne, and P.A. Seck. "Assessing the Effect of Consumer Purchasing Criteria for Types of Rice in Togo: A Choice Modeling Approach.” Agribusiness 31(2015):433-52.

Flaherty, K., R. Asare, G. Essegbey, and N. Beintema. Agricultural ReD Indicators Factsheet Updated: Ghana. Agricultural Science and Technology Indicators (ASTI), IFPRI, Washington, DC, 2018

Friedman, J.H., and W. Stuetzle. "Projection Pursuit Regression." Journal of the American Statistical Association 76(1981):817-23.

Gençay, R., and X. Yang. "A Forecast Comparison of Residential Housing Prices by Parametric Versus Semiparametric Conditional Mean Estimators.” Economics Letters 52(1996):129-35.

Godfrey, L. “Testing for Multiplicative Heteroscedasticity." Journal of Econometrics 8(1978):227-36.

Gyimah-Brempong, K., and O. Kuku-Shittu. "Evolution of Rice Consumption and Demand Patterns." The Nigerian Rice Economy: Policy Options for Transforming Production, Marketing, and Trade. K. Gyimah-Brempong, M.E. Johnson, and H. Takeshima, eds. Washington, D.C.: International Food Policy Research Institute (IFPRI), 2016.

Halvorsen, R., and R. Palmquist. "The Interpretation of Dummy Variables in Semilogarithmic Equations." American Economic Review 70(1980):474-75.

Halvorsen, R., and H.O. Pollakowski. "Choice of Functional Form for Hedonic Price Equations." Journal of Urban Economics 10(1981):37-49. 
Hastie, T., and R. Tibshirani. “Generalized Additive Models.” Statistical Science 1(1986):297-310.

Hastie, T., and R. Tibshirani. Generalized Additive Models. Wiley StatsRef: Statistics Reference Online, 2014. Internet site: https://doi.org/10.1002/9781118445112.stat03141

Haupt, H., J. Schnurbus, and R. Tschernig. “On Nonparametric Estimation of a Hedonic Price Function.” Journal of Applied Econometrics 25(2010):894-901.

Jordan, J.L., R.L. Shewfelt, S.E. Prussia, and W.C. Hurst. "Estimating Implicit Marginal Prices of Quality Characteristics of Tomatoes." Southern Journal of Agricultural Economics 17(1985):139-46.

Kane, G.Q., G.L. Mabah Tene, J.J. Ambagna, I. Piot-Lepetit, and F. Sikod. “The Impact of Food Price Volatility on Consumer Welfare in Cameroon.” WIDER Working Paper No. 2015/013, 2015.

Kassie, G.T. "Economic Valuation of the Preferred Traits of Indigenous Cattle in Ethiopia." Ph.D. dissertation, ChristianAlbrecht University of Kiel, 2007.

Kotchofa, P. "To What Extent Do Household Expenditure and Prices Affect the Demand for Rice in Northern Ghana?" Invited presentation at the Southern Agricultural Economics Association Annual Meeting, Jacksonville, Florida, February 2-6, 2018.

Kumashiro, T., K. Futakuchi, M. Sié, M-N. Ndjiondjop, and M.C.S. Wopereis. "A Continent-wide, Product-oriented Approach to Rice Breeding in Africa.” Realizing Africa's Rice Promise. M.C.S. Wopereis, D.E. Johnson, N. Ahmadi, E. Tollens, and A. Jalloh, eds. Wallingford, OX and Boston, MA: CAB International, 2013.

Kwong, L.M.K., D. Cyr, J. Kushner, and T. Ogwang. "A Semiparametric Hedonic Pricing Model of Ontario Wines." Canadian Journal of Agricultural Economics 59(2011):361-81.

Kwong, L.M.K., T. Ogwang, and L. Sun. "Semiparametric Versus Parametric Hedonic Wine Price Models: An Empirical Investigation." Applied Economics Letters 24(2017):897-901.

Ladd, G.W., and V. Suvannunt. "A Model of Consumer Good Characteristics.” American Journal of Agricultural Economics 58(1976):504-10.

Lancaster, K.J. “A New Approach to Consumer Theory.” Journal of Political Economy 74(1966):132-57.

Landajo, M., C. Bilbao, and A. Bilbao. "Nonparametric Neural Network Modeling of Hedonic Prices in The Housing Market." Empirical Economics 42(2012):987-1009.

Lee, D.E. "Nonparametric Estimation of a Hedonic Price Model: A South African Case Study." Studies in Economics and Econometrics 37(2013):41-62.

Lisi, G. "On the Functional Form of The Hedonic Price Function: A Matching-Theoretic Model and Empirical Evidence." International Real Estate Review 16(2013):189-207.

Magrini, E., J. Balie, and C. Morales-Opazo. "Price Signals and Supply Responses for Staple Food Crops in Sub-Saharan Africa." Applied Economic Perspectives and Policy 0(2017):1-21.

Martins-Filho, C., and O. Bin. "Estimation of Hedonic Price Functions Via Additive Nonparametric Regression." Empirical Economics 30(2005):93-114.

Mason, C., and J.M. Quigley. “Non-Parametric Hedonic Housing Prices.” Housing Studies 11(1996):373-85.

Meese, R., and N. Wallace. "Nonparametric Estimation of Dynamic Hedonic Price Models and the Construction of Residential Housing Price Indices.” Real Estate Economics 19(1991):308-32.

Naseem, A., S. Mhlanga, A. Diagne, P.Y. Adegbola, and G.S. Midingoyi. "Economic Analysis of Consumer Choices Based on Rice Attributes in the Food Markets of West Africa - The Case of Benin." Food Security 5(2013):575-89.

National Cereals Research Institute. Rice. 2021. Internet site: https:/www.ncribadeggi.org.ng/index.php/services/ programmes?start $=5$

Ndindeng, S.A., A. Candia, D.L. Mapiemfu, V. Rakotomalala, N. Danbaba, K. Kulwa, P. Houssou, S. Mohammed, O.M. Jarju, S.S. Coulibaly, E.A. Baidoo, J. Moreira, and K. Futakuchi. "Valuation of Rice Post-Harvest Losses in Sub-Saharan Africa and its Mitigation Strategies." Rice Science 28(2021a):1-5.

Ndindeng, S.A., E.E. Twine, G. Mujawamariya, R. Fiamohe, and K. Futakuchi. "Hedonic Pricing of Rice Attributes, Market Sorting, and Gains from Quality Improvement in the Beninese Market." Agricultural and Resource Economics Review 50(2021b): 170-86.

Ndindeng, S.A., K. Futakuchi, E. Twine, G. Mujawamariya, and E. Duveiller. "Towards Understanding Rice Grades and Quality Traits Across Markets in West Africa and Madagascar." AfricaRice Working Paper, 2020.

Ndindeng, S.A., J.T. Manful, K. Futakuchi, D.L. Mapiemfu, J.M. Akoa-Etoa, J. Bigoga, E.N. Tang, S. Graham-Acquaah, and J. Moreira. "A Novel Artisanal Parboiling Technology for Rice Processors in Sub-Saharan Africa." Food Science \& Nutrition 3(2015):557-68.

Obih, U., and L.S. Baiyegunhi. "Willingness to Pay and Preference for Imported Rice Brands in Nigeria: Do Price-Quality Differentials Explain Consumer Inertia?" South African Journal of Economic and Management Sciences 20(2017):1-11.

Pace, R.K. "Nonparametric Methods with Applications to Hedonic Models." Journal of Real Estate Finance and Economics 7(1993):185-204.

Pace, R.K. "Parametric, Semiparametric, And Nonparametric Estimation of Characteristic Values Within Mass Assessment and Hedonic Pricing Models." Journal of Real Estate Finance and Economics 11(1995):195-217. 
Parmeter, C.F., D.J. Henderson, and S.C. Kumbhakar. "Nonparametric Estimation of a Hedonic Price Function." Journal of Applied Econometrics 22(2007):695-99.

Ramsey, J.B. "Tests for Specification Errors in Classical Linear Least Squares Regression Analysis." Journal of the Royal Statistical Society 31(1969):350-71.

Republic of Cameroon. National Strategy for Rice Growing in Cameroon (MILLING) III. Republic of Cameroon, 2009. Internet site: https://riceforafrica.net/nrds-page

Republic of Ivory Coast. Revised National Rice Development Strategy for the Cote d'Ivoire Rice Sector (NRDS) 2012-2020. Republic of Ivory Coast, 2012. Internet site: https://riceforafrica.net/nrds-page

Rosen, S. "Hedonic Prices and Implicit Markets: Product Differentiation in Pure Competition." Journal of Political Economy 82(1974):34-55.

Rutsaert, P., M. Demont, M. Ndour, and E. Tollens. "Competitive Rivals: Willingness-To-Pay for Senegal River Valley Versus Imported Rice.” Conference Paper, II Workshop on Valuation Methods in Agro-food and Environmental Economics, Barcelona, July 2-3, 2009.

Sanni, K.A., A.A. Touré, A. Diagne, F. Bachabi, R. Murori, R.K. Singh, and M. Sié. "Rice Varietal Release Systems in Africa." Realizing Africa's Rice Promise. M.C.S. Wopereis, D.E. Johnson, N. Ahmadi, E. Tollens, and A. Jalloh, eds. Wallingford, OX and Boston, MA: CAB International, 2013.

Slayton, T. "Rice Crisis Forensics: How Asian Governments Carelessly Set the World Rice Market on Fire." Working Paper No. 163, Center for Global Development, 2009.

StataCorp. Stata: Release 16, Statistical Software. College Station, TX: StataCorp LLC, 2019.

Takeshima, H., and A. Maji. "Varietal Development and the Effectiveness of Seed Sector Policies: The Case of Rice in Nigeria." Nigeria Strategy Support Program Working Paper 34, IFPRI, 2016.

Tollens, E. "Markets and Institutions for Promoting Rice for Food Security and Poverty Reduction in Sub-Sahara Africa." African Crop Science Journal 15(2007):237-42.

Tollens, E., M. Demont, M. Sie, A. Diagne, K. Saito, and M.C.S. Wopereis. "From WARDA to AfricaRice: An Overview of Rice Research for Development Activities Conducted in Partnership in Africa.” Realizing Africa's Rice Promise. M.C.S. Wopereis, D.E. Johnson, N. Ahmadi, E. Tollens, and A. Jalloh, eds. Wallingford, OX and Boston, MA: CAB International, 2013.

Tondel, F., C. D'Alessandro, I. Hathie, and C. Blancher. "Rice Trade and Value Chain Development in West Africa: An Approach for More Coherent Policies.” Discussion Paper No. 283, ECDPM and IPAR, 2020.

United States Department of Agriculture (USDA). Nigeria Grain and Feed Update. GAIN Report, 2018. Internet site: https://apps.fas.usda.gov/newgainapi/api/report/downloadreportbyfilename?filename=Grain\%20and\%20Feed\%20Update Lagos_Nigeria_12-6-2018.pdf

United States Department of Agriculture (USDA). PSD Datasets: Grains and Pulses. 2020. Internet site: https://apps.fas. usda.gov/psdonline/app/index.html\#/app/downloads

Unnevehr, L.J. “Consumer Demand for Rice Grain Quality and Returns to Research for Quality Improvement in South East Asia.” American Journal of Agricultural Economics 68(1986):634-41.

Unnevehr, L.J. "Methodologies for Measuring Consumer Preferences and Welfare Effects of Quality Improvement." Consumer Demand for Rice Grain Quality. M.C.S. Unnevehr, L.J.B. Duff, and B.O. Juliano, eds. Manila and Ottawa: IRRI and IDRC, 1992.

Voon, J.P., and G.W. Edwards. "Research Payoff from Quality Improvement: The Case of Backfat Depth in Pigs." Journal of Agricultural Economics 42(1991):66-76.

Waithaka, M., M. Mugoya, A. Ajayi, F. Okelola, and K. Tihanyi. Nigeria Brief 2018 - The African Seed Access Index. 2019. Internet site: https://tasai.org/wp-content/themes/tasai2016/img/tasai_nigeria_brief_2018_lr.pdf

White, H. "A Heteroscedasticity Consistent Covariance Matrix Estimator and a Direct Test of Heteroscedasticity." Econometrica 48(1980):817-18.

Wooldridge, J.M. “A Test for Functional Form Against Nonparametric Alternatives.” Econometric Theory 8(1992):452-75.

World Bank. PPP Conversion Factor, Private Consumption (LCU per International \$). International Comparison Program, World Development Indicators database, 2020. Internet site: https://data.worldbank.org/indicator/PA.NUS.PRVT.PP

Cite this article: Twine, E.E., S. A. Ndindeng, G. Mujawamariya, and K. Futakuchi (2022). "Pricing Rice Quality Attributes and Returns to Quality Upgrading in Sub-Saharan Africa.” Journal of Agricultural and Applied Economics 54, 175-196. https:// doi.org/10.1017/aae.2022.3 